\title{
Obstacles to Process Integration along the Supply Chain:
}

\section{Manufacturing Firms Perspective}

\author{
Tumaini Mujuni Katunzi \\ School of Information Management \& Engineering \\ Shanghai University of Finance and Economics \\ 369, Zhongshan North Road No.1, Shanghai, China \\ E-mail: tumainik7@gmail.com
}

Received: December 3, $2010 \quad$ Accepted: March 29, 2011 doi:10.5539/ijbm.v6n5p105

\begin{abstract}
Supply chain management has generated much interest in recent years for a number of reasons.

Many managers now realize that actions taken by one member of the chain can influence the profitability of all others in the chain. Firms are increasingly thinking in terms of competing as part of a supply chain against other supply chains, rather than as a single firm against other individual firms.

Many companies have successfully implemented supply chain concepts with spectacular results. Efficient supply chains have enabled these firms to compete better. What were the reasons for their successes? What were the obstacles these firms faced in their journeys to achieve integration in their networks? How were they able to overcome these obstacles?

Using review of the literature, this article reveals the dominating factors motivating manufacturing firms to engage in supply chain management activities, the barriers they face upon implementation, the strategies or bridges used to overcome the barriers, and the benefits that are available to successful companies. The major barriers identified by this paper include; silo mentality, lack of supply chain visibility, lack of trust, lack of knowledge and activities causing the bullwhip effect.
\end{abstract}

Keywords: Supply chain management, Supply chain, Process integration, Obstacles and barriers

\section{Introduction}

The ultimate goal in supply chain management (SCM) is to create value for the end customers as well as the firms in the supply chain network. To accomplish this, firms in the supply chain network must integrate process activities internally and with other firms in the network. The term process integration means coordinating and sharing information and resources to jointly manage a process. Integration is a process of redefining and connecting parts of a whole in order to form a new one (Craft, 2006).

Process integration can sometimes be an extremely difficult task, because it requires proper training and preparedness; willing and competent trading partners; and, potentially, a change in one or more organizational cultures. However, the benefits of collaboration and information sharing can be significant: reduced supply chain costs, greater flexibility to respond to market changes, less supply chain safety stock, higher quality levels, reduced time to market, and a better utilization of resources (Chopra and Mendhl, 2001).

According to Juanqiong et al, (2007), a successful SCM requires a change from managing individual functions to integrating activities into key supply chain processes. An example scenario: the purchasing department places orders as requirements become appropriate. Marketing, responding to customer demand, communicates with several distributors and retailers as it attempts to satisfy this demand. Shared information between supply chain partners can only be fully leveraged through process integration.

Supply chain business process integration involves collaborative work between buyers and suppliers, joint product development, common systems and shared information. According to Brown (1998) operating an integrated supply chain requires continuous information flow. However, in many companies, management has reached the conclusion that optimizing the product flows cannot be accomplished without implementing a process approach to the business. This paper intends to reveal the challenges that firm come across on attempting 
to integrate business functions along the supply chain.

\subsection{Supply Chain Integration}

As companies work toward integrating their internal functions and begin to understand the workings of the larger systems to which they belong, they begin to generate clearer understanding of the scope of supply chain integration. As researchers and practitioners from different disciplines start to work together, they, too, are beginning to reach a common understanding of supply chain integration, although a common definition is still lacking in both academia and the business community.

In their seminal work, Lawrence and Lorsch (2000) defined integration as, "the quality of the state of collaboration that exists among departments that are required to achieve unity of effort by the demands of the environment". While this definition refers to integration internal to a firm or organization, our emphasis here goes beyond the firm and encompasses external entities that are players in a supply chain.

Bowersox, Closs and Stank (2001) have classified integration in a supply chain context in six different types. These are customer integration, internal integration, material and service supplier integration, technology and planning integration, measurement integration and relationship integration.

Stevens (2003) identified four stages of supply chain integration, where stage I represented the fragmented operations within the individual company. Stage II focused on limited integration between adjacent functions, e.g. purchasing and materials control. Stage III required the internal integration of the end-to-end planning in the individual company and stage IV represented the true supply chain integration including upstream to suppliers and downstream to customers.

Lee (2000) outlines three dimensions of supply chain integration: information integration, coordination and resource sharing, and organizational relationship linkage. Information integration refers to the sharing of information and knowledge among the members in the supply chain, including sales forecasts, production plans, inventory status and promotion plans. Coordination and resource sharing refers to the realignment of decisions and responsibility in the supply chain. Organizational relationship linkages include communication channels between the members in the supply chain, performance measurement and sharing of common visions and objectives.

Integrating a supply chain is an incremental process, with priority typically given to the highest potential returns on investment (Ketchen and Hult 2006). The figure 1 below presents a supply chain integration model, starting with the identification of key trading partners; the development of supply chain strategies; aligning the strategies with the key process objectives; developing process performance measures; internally integrating these key processes; developing supply chain performance measures for each process key; externally integrating key processes with supply chain trading partners; extending process integration to second-tier supply chain participants; and then, finally, reevaluating the integration model periodically.

\section{Insert $<$ Figure 1> about here}

For each firm's products and services, it is important to identify the critical trading partners that will enable the successful sale and delivery of the end product to the final customer. Identifying only the primary trading partners allows the firm to concentrate its time and resources on managing the important links with these companies, enabling the supply chain to perform well, (Bardi et al. 2001).

The key processes and the methods used to integrate and manage process links among supply chain partners will vary based on the internal structure of the firm, the prevailing economic conditions in the market place and the nature of existing relationships within the supply chain. In some cases, it may be best to integrate only one key process with a trading partner; while with the other partners more processes will be integrated.

Supply chain trading partners must concentrate on sharing sales and forecast information, along with information on new products, expansion plans, new processes, and new marketing campaigns in order to maximize profits for the entire supply chain membership, not just for themselves. The way information is communicated plays an extremely important role in external process integration (Lambert, 2008).

\subsection{The Benefits of Supply Chain Integration}

The most frequently cited reason for firms to engage in supply chain activities is in response to threats and overtures from competitors, both domestic and global. High levels of supply chain performance occur when the strategies at each of the firms fit well with overall supply chain strategies. Thus, each firm must understand its role in the supply chain, the needs of the ultimate customer, the needs of its immediate customers, and how these needs translate into internal operations requirements and the requirements being placed on suppliers. Once these 
needs and the products and services themselves can be communicated and transported through the supply chain effectively, successful supply chain management and its associated benefits will be realized.

Successful supply chain integration occurs when the participants realize that supply chain management must become part of all of the firms' strategic planning process, in which objectives and policies are jointly determined based on the final customer's needs and what the supply chain as a whole does well (Wisner et al.2006). If a firm is successful at overcoming the significant and complex barriers to integrating supply chains, substantial benefits can be realized ranging from satisfied customers to lower costs to improved financial performance (Fawcett and Magnan, 2002). The range benefits that can accrue to companies that are able effectively manage and work in their supply chains includes:

- Increased market share and sales growth

- Reduced inventory levels

- Reduced SCM costs

- Decreased order cycle/fulfillment time

- Increased asset and capital utilization

- Improved delivery performance

- Flexibility in meeting/responding to customer requirements

- Improved return on assets and sales

- Increased forecast accuracy

- Reduced cash-to-cash cycle time

Revenue growth fueled by increased responsiveness occurring at lower cost using fewer assets translates into stellar performance. As the demands of customers and stakeholders increase, and global competition grows, supply chain management, when properly implemented, obviously has the capability to deliver improvements across multiple dimensions of performance.

\section{The Obstacles to Supply Chain Integration}

Under this section we shall discuss the overriding obstacles that impede the process integration along the supply chain. Together with the obstacles, we underlay some remedial measures that can be implemented to overcome them. According to Chopra and Mendhl (2001), a number of factors can impede external process integration along the supply chain, causing information distortion, longer cycle times, stock-outs, and bullwhip effect, resulting in higher overall cost and reduced customer service capabilities. Table 1 summarizes these obstacles. We shall discuss these obstacles in details under this section;

Insert $<$ table $1>$ about here

\subsection{Silo Mentality}

In many instances, firms have not considered the impact of their actions on the supply chain and its long-term competitiveness and profitability. According to Wisner et al (2006), the "I win, you lose" silo mentality manifests itself in the form of using cheaper suppliers, paying little attention to the needs of customers, and assigning few resources to new products and service design. Eventually, these firms will create quality, cost, delivery timing, and other customer service problems that are detrimental to the supply chain. Cachon (2005), in his paper, describes silo mentality as the most significant obstacle to overcome in supply chain management of most companies. Internally, the silo effect can also be present among departments. The transportation manager for instance, may be trying to minimize total annual transportation costs while inadvertently causing safety stocks to be higher, shortages to occur, and customer service levels to deteriorate. To overcome the silo mentality, the firm must strive to align supply chain goals and the goals and incentives of the firm. Functional decisions must be made while considering the impact on the entire firm's profit and those of the supply chain. Performance reviews of managers must include their ability to integrate processes internally and externally and to meet the overall supply chain goals.

\subsection{Lack of supply chain visibility}

Lack of information visibility along the supply chain is a common supply chain process integration problem. In a 2002 survey, two-thirds of manufacturers had not yet successfully synchronized their supply chain operations with those of their trading partners (Cachon and Fisher, 2000). Additionally, two-thirds of the respondents said 
they used different supply chain management applications than their partners, which prevented access to valuable external data, resulting in limited information visibility.

In the absence of supply chain visibility, trading partners have to carve out data from their ERP (enterprise resource planning) or legacy systems and then send it to one another where it then has to be uploaded to other systems prior to the data being shared and evaluated, the time lost can mean lost end customers and higher costs through the supply chain membership.

\subsection{Lack of trust}

Successful process integration between partners requires trust, as with silo mentality and lack of information visibility, trust is seen as the major stumbling block in supply chain management. Trust occurs over time between supply chain partners, as each participant earns trust while it builds its reputations among the other businesses.

Even though this sounds impossible, relationships employing trust result in win-win or win-win-win for the participants. Spalding Holding collaborates with Wal-Mart, resulting in win-win for both companies. Wal-Mart gives Spalding its forecast and point-of-sale data, which allows Spalding to keep its inventory levels down and serve Wal-Mart's needs better. As a result, Wal-Mart stocks out of Spalding goods less frequently and it now has a better understanding of Spalding's capacity and cost (Wisner et al, 2006).

Unfortunately, company practices and human nature will not change overnight. Until parties understand that it is in their own best interest to trust each other and share information, supply chain management success will be an uphill battle. For example, Boeing has been running against a trust barrier with some of its suppliers. Boeing engineers and their suppliers pass design documents back and forth as if they were in the same company. The technology that allows this is causing trust problems for Boeing. The company has been suspecting its suppliers to pass technogly to their close competitors (Lambert, 2008).

\subsection{Lack of knowledge}

Companies have been moving toward collaboration and process integration for years, and it is just recently that technology has caught up with this vision, allowing the process integration across an extended supply chain. In a survey of 122 executives practicing supply chain management, 43 percent said lack of core supply chain management skills and knowledge was the greatest obstacle within their own organizations, and 54 percent echoed this opinion for their trading partners. Getting the network of firms to work together successfully, though, requires managers to use subtle persuasion and education to get their own firm and their trading partners to do the right things.

The cultural, trust, and process knowledge differences in firms are such that firms successfully managing their supply chain must spend significant amount of time influencing and increasing the capabilities of themselves and their partners. Change and information sharing can be threatening to people; they may fear for their job security, particularly if outsourcing accompanies integration. Additionally, as firms construct their supply chain information infrastructure, they may find themselves with multiple ERP systems, a mainframe manufacturing application, and a desktop analysis and design software that all need to be integrated both internally and externally. Thus, firms must realize that the people to be using the system must be involved earlier on, in terms of purchase decision, the implementation process, and in training. For all organizations, successful supply chain management requires a regiment of ongoing training. When education and training are curtailed, innovation cannot occur, and innovation fuels supply chain competitiveness (Wisner et al, 2006).

\subsection{Activities causing the bullwhip effect}

The variability increases in moving up the supply chain from consumer to grocery store to distribution center to central warehouse to factory is known the bullwhip effect. The bullwhip effect has been experienced by many students playing the "Beer Distribution Game." (Chen \& Samroengraja (2000). The costs of this variability are high inefficient use of production and warehouse resources, high transportation costs, and high inventory costs, to name a few. In their publication, Lee et al (1997), identified four major causes of bull whip effect, these causes and methods used to counteract them will be discussed in this section for the purpose of getting deep understanding of this obstacle to process integration along the supply chain.

\subsubsection{Demand updating}

Whenever a buying firm places an order, the selling firm uses that information as a predictor of future demand. Based on this information, sellers update their demand forecasts and the corresponding orders placed with their suppliers, Cachon (2005). As lead time grows between orders placed and deliveries, then the safety stock also 
grow and are included in any order as they pass up the supply chain. Thus, fluctuations are magnified as orders vary from period to period and as the review period change, causing frequent demand forecasting updating. According to Craft (2006), one solution to this problem is to make actual demand data available to the firm's suppliers. Better yet, if all point-of-sale data are made available to the upstream tiers of suppliers, all supply chain members can then update their demand forecast less frequently, using the same data.

\subsubsection{Order Batching}

In a typical buyer/supplier scenario, demand draws down inventory until a reorder point is reached wherein the buyer places an order with the suppler. Inventory levels, safety stocks, and the desire to order full truckloads or containers loads of materials may cause orders to be placed monthly or ever less often, or at a varying time intervals. This type of order batching amplifies demand variability and adds to a bullwhip effect. Another type of order batching can occur when sales people need to fill end-of-quarter or end-of-year sales quotas, or when buyers desire to finish year-end budget allotments. As with forecast updating, information visibility and use of more frequent and smaller order sizes will tend to reduce the order batching problem.

\subsubsection{Price Fluctuations}

When suppliers have special promotions, quantity discounts, or other special price discounts, these price fluctuations results in significant forward buying activities on the part of buyers, who are stocking up to take advantage of low price offers. Forward buying occurs between retailers and consumers, between distributors and retailers, and between manufacturers and distributors due to pricing promotions at each stage of the supply chain, all contributing to erratic buying patterns and, consequently, the bullwhip effect. If these price discounts become common place, firms will stop buying when prices are undiscounted and buy only when discounted prices are offered, even further contributing to bullwhip effect. This may cause manufacturers to vary capacity by scheduling overtime and undertime for employees, finding places to store stockpiles of inventory, paying more for transportation, and dealing with higher levels of inventory damage as inventory are held for longer periods.

The obvious measure to reduce the problem caused by fluctuating prices is to eliminate price discounting among the supply chain's members. Manufacturers can reduce the forward buying by offering uniform wholesale prices to its customers. Many retailers have adopted everyday low prices (EDPL), while eliminating sales or promotions that cause forward buying. Similarly, buyers can negotiate with the suppliers to offer EDPL, while curtailing promotions.

\subsubsection{Rationing and Shortage Gaming}

Rationing occurs when demand exceeds a supplier's finished goods available; and, in this case, the supplier may allocate product in proportion to what buyers ordered. Thus, is the supply of goods is 75 percent of the total demand; buyers would be allocated 75 percent of what they ordered. When buyers figure out the relationship between their orders and what is supplied, they tend to inflate their orders to satisfy their real needs, (Amrani et al, 2006), . This strategy is termed as shortage gaming. Obviously, this further escalates the supply problem, as the supplier struggle to keep up with these higher demand levels. When, on the other hand, production capacity eventually equals demand and orders are filled completely, demand suddenly drops to less-than-realistic levels, as the buying firms try to unload their excess inventories. A good example is on the gasoline supplies; as soon as consumers think a shortage is looming, demand suddenly increases as people top off their tanks and otherwise try to stockpile gasoline, which itself creates a real shortage (Lambert, 2008). When these types of shortages occur due to gaming, suppliers can no longer discern the true demand; and this result in unnecessary additions to production capacity, warehouse space and transportation investments.

One way to eliminate shortage gaming is for sellers to allocate short supplies based on the demand histories of customers. In that way, customers are essentially not allowed to exaggerate orders. And, of course, the sharing of capacity and inventory information between a manufacturer and its customers can also help to eliminate customers' fears regarding shortages and eliminating gaming. A number of rational decisions on the part of buyers and suppliers tend to cause the bullwhip effect. When trading partners use the preceding strategies to reduce the bullwhip effect, the growth of information sharing, collaboration, and process integration occurs along the supply chain. Firms that strive to share data, forecasts, plans, and other information can significantly reduce the bullwhip effect.

\section{A theoretical model to overcome obstacles to integration along the supply chain}

Integration of internal process with external supply chain network could be improved through communication, partnerships, alliances and cooperation (Morrissey and Pittaway, 2004). The pillars of supply chain integration 
are cooperation, collaboration, information sharing, trust, partnership, shared technology, and a fundamental shift away from managing individual function processes, to managing integrated chains of process.

Relational exchange theory (RET) offers the notion of embeddedness in a relationship (Lee, 2001), which evokes a "moral control" (Lambert, 2008) that diminishes the desire for opportunism between trading partners. Relational exchange theory proposes the nature of the exchange relationship between entities is directed by the level of expectation that the relationship will be rewarding The concept of embeddedness in social relationships explains the departure from "pure economic motives" as firms "become overlaid with social content that carries strong expectations of trust and abstention from opportunism," (Lee, 2001). Craft (2006) explains that relationships devoid of trust will be less efficient due to the energies expended to focus on safeguarding activities necessary to check opportunism. Thus, relationships characterized by lack of trust are less likely to survive in the marketplace as competitive pressures "select out inefficient relationships and firms that enter into them, leaving behind the more efficient, trust-based ones" (Chopra and Mendhl, 2001).

This relationship theory explaining choice of governance modes is based on possession of and dependence on resources. Resource dependence reflects the importance to a firm of obtaining resources from another firm to accomplish objectives (Wisner et al., 2006). An underlying assumption of resource dependency theory is that most organizations are not self-sufficient; resulting in dependence upon other firms to obtain critical resources Domenica (2002) claims that supply chain should actually be efficient and effective. In this case, efficient means to minimize resources use to accomplish specific outcomes, and effective in terms of designing distribution channels. Efficiency is measured by delivery performance, product quality, back orders and inventory levels. Whereas effectives is measured by service quality and the service needs. Therefore for the company/firm to survive competition, depends on how well it meets customer preferences in terms of service, cost, quality, and flexibility, by designing a supply chain which will be more effective and efficient than competitors.

A well integrated supply chain is both effective and efficient. Figure 2, below shows a proposed theoretical integrated supply chain model for combating obstacles discussed earlier in this paper. Information visibility which ensures two-way information flow between the firm and suppliers, as well as the firm with its customers, nowadays firms has opportunities to utilize supply chain open innovations or technology to integrate with other members of the chain. Visibility or information sharing, reduces inventory costs, bullwhip effects and also ensures timely delivery. Trust although is more of a moral or cultural aspect is a stepping stone prior to integration. Firms are likely to integrate with members they can trust, rather than the ones labeled as their competitors.

Employees training and involvement before adopting new technology or innovation will not only empower them but also eliminate the innovation-adaptation phobia. Introduction of uniform wholesale pricing, instead of discount prices for members in the chain, will further reduce the occurrence of bull-whip effects. Customer preferences, market size and customer demand information will reduce or minimize the chances of shortage supply, order batching and eventually the bull-whip manifestations.

\section{Insert $<$ t figure $2>$ about here}

\section{Managerial implications}

The practice of supply chain management is a very recent phenomenon, as many organizations are just now beginning to realize the benefits and the problems that accompany an integrated supply chain. Supply chain management is an incredibly complex undertaking involving cultural change among most or all of the participants, investment and training in new software and communication systems, and a change or realignment of the competitive strategies employed among the participating firms(Chen et a., 2003).

As competitive situations, products, technology, and customers change, the priorities for the supply chain also must change, requiring supply chains to be ever more flexible to respond quickly to these changes. As we look at the most recent practices and the future trends of supply chain management, a number of issues present themselves as areas that need to be addressed including the expansion of supply chain, increasing supply chain responsiveness, creating an environmental friendly supply chain and reducing total supply chain costs.

\section{Limitations and directions for further research}

The study provides a current portrait, on the obstacles that are likely to be faced by firms during the implementation of supply chain integration strategy. Our approach was merely based on manufacturing firms dealing with tangible products. This necessitates further studies with an emphasis on other sectors such as service industries. Other aspects such as structures and business processes would be relevant to study more closely with regard to possible difference in obstacles among different firm categories. 


\section{Conclusion}

The emergence of the Supply Chain Management innovations has allowed firms to compete effectively and efficiently in both domestic and international markets. It is eminent that information technology has surfaced as a key instrument to help organizations achieve greater coordination and collaboration among supply chain partners and mechanize the supply chain process. This has created competitive pressures as manufacturers and distributors are forced to become more responsive to the retailers and consumers needs. These pressures are make it necessary for the manufacturing firms to reduce costs, decrease lead times, and improve their overall operating competences. As a result, manufacturers are forced to better manage the supply chain and to improve manufacturing efficiency and logistics operations while remaining reactive to changing market conditions and customer demands. The increasingly intricate global relationships among suppliers, manufacturers, distributors, retailers and consumers amalgamate these pressures.

\section{References}

Amrani, E.R., Rowe, F., \& Maronna, B. G. (2006). The effects of enterprise resource planning Implementation strategy on cross-functionality. Information Systems Journal, 16, 79-104.

Bardi. E, T. Raghunathan, and P. K. Bagchi. (2001). Logistics Information Systems: The Strategic Integration a Reality. Council of Logistics Management. Oak Brook, IL.

Bowersox, D. J., Closs.D, and Stank T. P. (2001). 21st Century Logistics: Making Supply Chain and Integration, 2nd Edition. Harvard Business School Press. Boston, MA.

Brown, A. (1998). Organizational Culture. 2nd edition. London: Financial Times

Cachon, G. (2005). Managing supply chain demand variability with scheduled ordering policies. Journal of Management Science, Vol.45, p 843-856.

Cachon, G., and M. Fisher. (2000). Supply Chain Inventory Management and the Value of Shared Information. Journal of Management Science, Vol.46, p 1032-1048.

Chen, F., \& Samroengraja, R. (2000). Information and Incentives in Supply Chain Management: The Stationary Beer Games. POMS, forthcoming.

Chen, H., Themistocleous, M., and Chiu, K. H. (2003). 'Inter-Organizational Application Integration: the Case of 15 Taiwan's SMEs', In Proceedings of the ISOneWorld Conference, April 23-25, Las Vegas, Nevada, USA, CD-ROM.

Chopra, S., and Meindl P. (2001). Supply Chain Management: Strategy, planning, and Operation. Upper Saddle River, New Jersey. Prentice-Hall, Inc. (pp 33-37).

Craft, N. (2006). Process integration in the supply chain. BMP think tank, Volvo IT business process innovation research, 37(8), 112.

Juanqiaong, G., Tingting. M., and Jingiing, L. (2007). A research on supply chain integration strategy based on virtual value net. Springer Boston, (pp887-891).

Ketchen Jr., G., \& Hult, T.M. (2006). Bridging organization theory and supply chain management: The case of best value supply chains. Journal of Operations Management, 25(2) 573-580

Lambert, D. M. (2008). Supply Chain Management: Processes, Partnerships, Performance, 3rd edition. McGraw Hill Press.

Lawrence P. R., and Lorsch J. W. (2000). Organization and Environment. Journal of Managing Differentiation Review, pp. 30-36. Pitman Publishing.

Lee H. L. (2000). Creating Value through Supply Chain Integration. Supply Chain Management Role of Top Management. Journal of Business Logistics, Vol. 15, no. 1.

Lee H.L., Padmanabhan V., and Whang S. (2007). The Bullwhip Effect in Supply Chains. Sloan Management Review, 38, no. 3p 93-102.

Magnan G. M., and Fawcett S. E. (2002). Supply Chain Barriers, Bridges and Benefits: Perspectives from the Literature. Decision Sciences Institute Annual Meeting Proceedings.

Stevens, G. C. (2003). Integrating the supply chain. International Journal of Physical Distribution and Materials Management, Vol. 19, No. 8 pp. 3--8. 
Wisner, J., Keong Leong, G., and Keah-Choon Tan. (2006). Principles of Supply Chain Management. A Balanced Approach. Beijing; Thomson.

Table 1. Summary of the obstacles to supply chain process integration along supply chain

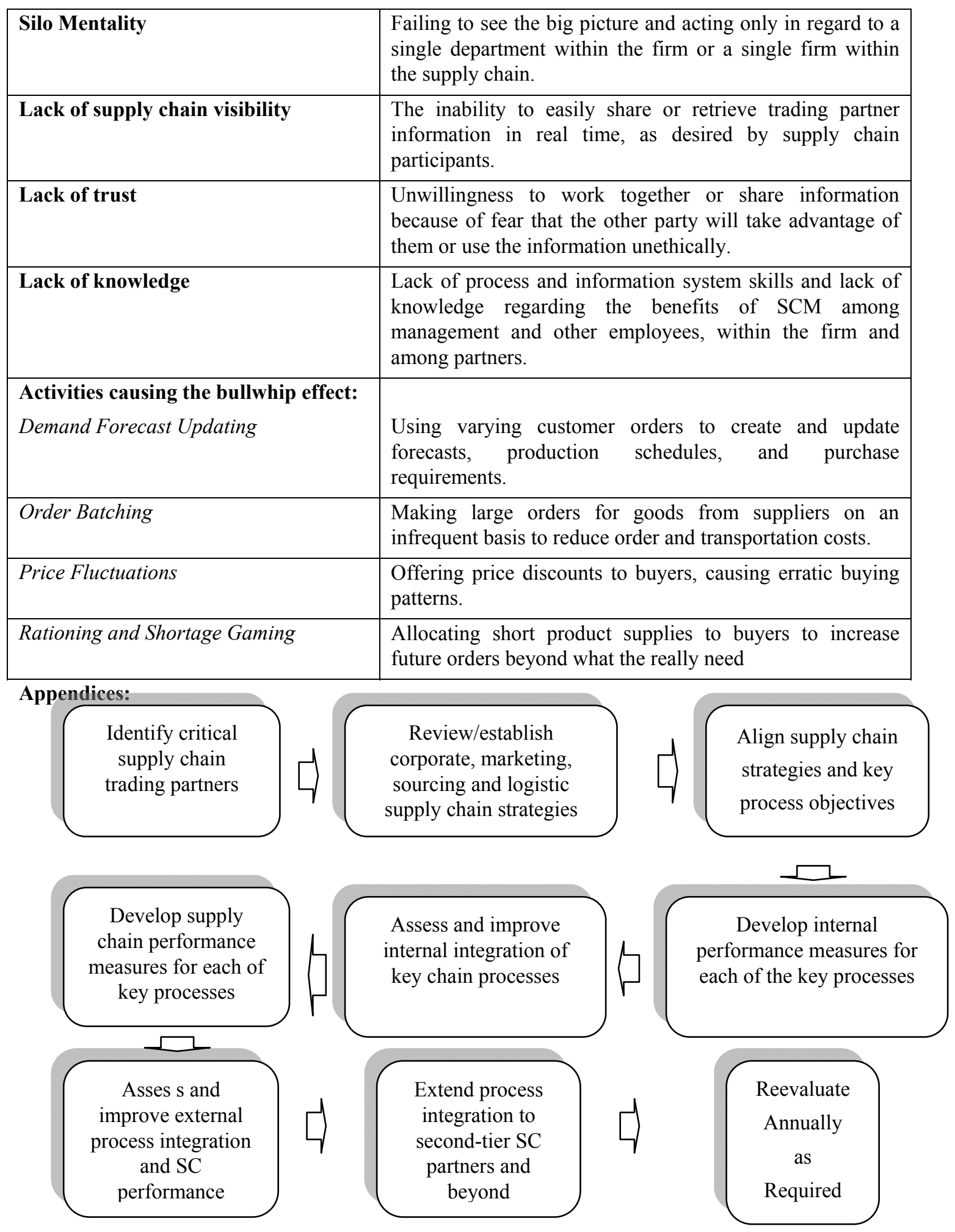

Figure 1. The supply chain process integration model; Source: Wisner et al, 2006 


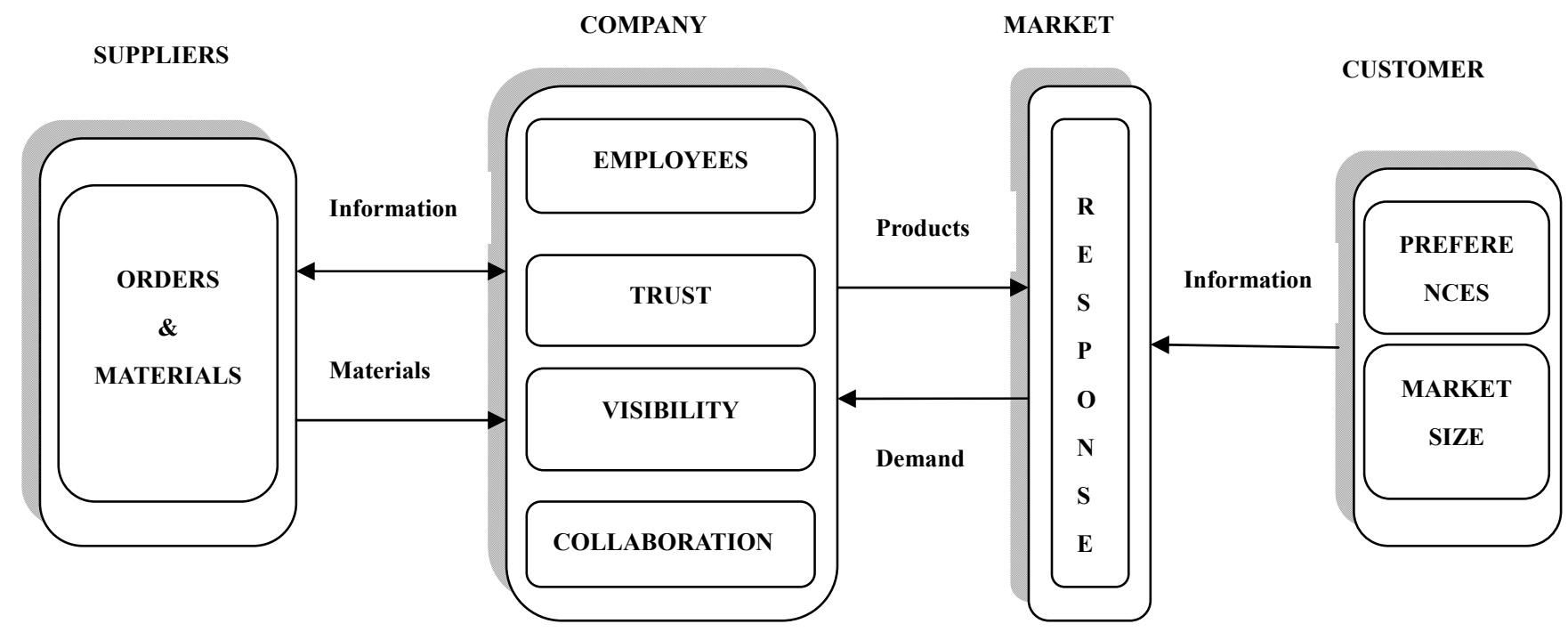

Figure 2. A theoretical supply chain integration model 